NASA Technical Memorandum 83712

\title{
An Analysis of Traction Drive Torsional Stiffness
}

Douglas A. Rohn and Stuart H. Loewenthal

Lewis Research Center

Cleveland, Ohio

Prepared for the

Fourth International Power Transmission and Gearing Conference sponsored by the American Society of Mechanical Engineers Cambridge, Massachusetts, October 8-12, 1984 
AN ANALYSIS OF TRACTION DRIVE

TORSIONAL STIFFNESS

Douglas A. Rohn and Stuart $H$. Loewenthal

National Aeronautics and Space Administration

Lewis Research Center

Cleveland, Ohto 44135

\section{ABSTRACT}

An analysis of the tangential compliance of elastic bodies in concentrated contact is applied to traction drive elements to determine their torsional stiffness. Both static loading and rotating conditions are considered. The effects of several design variables are shown. The theoretical torsional stiffness of a fixed ratio multiroller traction drive is computed and compared to experimental values. The analysis shows that the torsional compliance of the traction contacts themselves is a relatively small portion of the overall drive system compliance. Comparison is also made to theoretical gear mesh stiffness.

\section{INTROOUCTION}

Traction power transfer occurs in a broad variety of mechanical mechanisms. Applications range from dry contacts such as a steel railroad locomotive wheel driving against a steel rail to elastomer coated discs handling sheets of paper in computer peripheral equipment. The large number of commercially available speed and special machinery traction drives are surprising to those unfamiliar with these devices [1]. The bulk of these applications involve lubricated, steel contacts. Power ratings range from fractional horsepower to, in a few cases, several hundred horsepower for high speed, high performance drives. Apart from their adjustable speed abllity, traction drives possess seldom matched high speed, low noise, smooth power transfer characteristics $[2,3]$. 
Power transmitting or speed changing drives are not the only application which can benefit from traction torque transfer. There is a large class of position orienting mechanisms for which the zero backlash, low torque ripple and high torsional stiffness characteristics of traction contacts is particularly well suited. Examples include antenna drive positioners, robotic hinges and pivots, satellite control moment gyros and a wide class of industrial servopositioning mechanisms.

While the transmitted power levels in posttioning-type mechanisms are typically low due to the low speed or start-stop nature of these mechanisms, the peak transmitted torque and required force are often high. Nevertheless, traction drive contacts can be reasonably sized since at these low speeds the bulldup of fatigue stress cycles is low and the avallable traction coefficient is high. Idealiy, the mechanism whether made up of traction elements or not, should operate smoothly under load when motion is required. Furthermore, hysteresis, breakaway torque and backlash should be at an absolute minimum while maximizing torsional stiffness between the driving and the driven element. The requirement for zero backlash and high stiffness is obvious from a control point of view since a direct, continuous, hard "link" between output and input motion is most desirable.

Traction drives are particularly well suited to satisfy these requirements. Smooth rollers in driving contact avoid the meshing errors and torque discontinuities of gear mechanisms as the load is passed between meshing teeth. Similarly, traction drive rollers are always in driving contact regardless of direction of tangential loading. Thus backlash is precluded.

The principal purpose of this investigation is to analytically model the torsional stiffness characteristics of a traction drive contact and to compare predicted torsional stiffness values to those determined experimentally for a 
complete traction drive system. Comparisons between gearset stiffnesses and those of equivalentiy sized, traction roller pairs are also made.

NOMENCLATURE

a contact ellipse semimajor axis, m (in.)

a' semimajor axis of static contact locked region, m (in.)

$b^{\prime}$ semiminor axis of static contact locked region, m (in.)

b" semiwidth of rolling contact locked region, $m$ (in.)

b contact ellipse semiminor axis, m (in.)

C compliance, $\mathrm{m} / \mathrm{N}(\mathrm{in.} / \mathrm{lbf})$

$\mathrm{C}_{\mathrm{T}}$ torsional compliance, rad/N.m (rad/in. lbf)

E modulus of elasticity, Pa (psi)

$\mathscr{E} \quad$ complete elliptic integral of second $k$ ind, argument $k$

$\mathscr{E}_{1}$ complete elliptic integral of second kind, argument $k_{1}$

5. complete elliptic integral of first kind, argument $k$

$\mathscr{F}_{1}$ complete elliptic integral of first kind, argument $k_{1}$

$F_{x}$ tangential force applled to contact, $N$ (IDf)

$G$ shear modulus, Pa (psi)

J cross-sectional polar moment of inertia, $m^{4}\left(i n .^{4}\right)$

$k$ ratio of rolling contact locked region semiwidth to contact ellipse semiwidth

k elliptic integral argument, $\left(1-b^{2} / a^{2}\right)^{1 / 2}$

$k_{1}$ elliptic integral argument, $\left(1-a^{2} / b^{2}\right)^{1 / 2}$

${ }^{k}$ torsional stiffness, N.m/rad (in. Ibf/rad)

$L \quad$ length of shaft, $m(i n$.

$N$ contact normal load, $N(1 b f)$

q constant

$R$ effective radius of curvature, $m(i n$.

$r$ rolling or transverse radius, $m$ (in.) 
T torque, N.m (in. Ibf)

U solid body surface speed, $\mathrm{m} / \mathrm{s}(\mathrm{in} / \mathrm{s})$

$x$ solid body surface motion, $m($ in.)

Greek

a effective radius ratio

$\Gamma$ geometric displacement function

$\delta$ static tangential displacement of one body, m (in.) solid body

$\theta$ solid body angular displacement, rad

r elasticity parameter

$\mu \quad$ maximum traction coefficient

$v$ Polsson's ratio

$\sigma_{0}$ maximum surface contact pressure, $\mathrm{Pa}(\mathrm{ps} 1)$

\section{Subscripts}

1 system elements

$x, y$ reference planes

1,2 contacting bodies

\section{ANALYSIS}

Tangential Force on Concentrated Contact

When two elastic bodies are brought into contact and loaded under a system of forces, deflections occur. When the load is a normal force, the deformation and contact area are given by the classical theory of Hertz. Addition of a tangential force produces a relative deflection of the bodies in the tangential direction. A magnified view of the contact under these conditions is shown in Fig. 1. If the bodies are rollers or balls which are allowed to rotate under these forces, fresh unstrained material passes through the effective contact region which increases the relative displacement of the bodies. A presentation of this problem and discussion of several classical solutions is given in [4]. 
Previous numerical and analytical solutions are reviewed in [5]. To set the ground work for the approach adopted here, a brief overview of the theory and prior solutions to this problem will be given. First, the case of dry contacts w111 be addressed.

The problem is treated as a boundary value problem in elasticity. The conditions to be satisfied are described in detail in [6]. In simplified terms, the first constraint is that the addition of a tangential force to the contact does not alter the Hertzian normal pressure distribution. Secondiy, all of the assumptions inherent to the Hertzian solution are retained, including nonwarping of the contact surface, bodies not too closely conforming in the contact area, body radil large in comparison with contact dimensions, and like elastic properties of the two bodies. Thirdiy, the contact region is divided into two zones: one with "microslip" or relative motion between the mating surfaces, and one where the two surfaces are "locked" together. In the slip region, the applied shear stress (traction force per unit area) is assumed to reach its limiting value, proportional to a constant traction coefficient, $\mu$, times the local normal pressure in accordance with Coulombic fiction. Within the locked region, the applied shear stress is less than $\mu$ times the normal pressure. Outside of the Hertzian contact area, traction is zero. The local deflection of a point on the surface with respect a distant point in the body is constant over the locked region, and varies over the silp region and outside the contact area. Far away from the contact, the strain is zero.

These considerations apply equaliy to the two cases of interest: static loading, and rolling under an applled tangential load. Historically, the tangential deflection problem of a rolling contact under tangential load has received greater attention [7,12]. Deformation in a steady rolling contact is viewed from a stationary coordinate system with the origin at the center of contact. Material of each contacting body flows through the contact region 
under a strain field which is invariant with time. The static case, which is static only in the sense there is no rolling (forces and deflection can vary with time) has been treated by itself $[6,13,16]$. However, little work has been conducted for the "start-up" condition which represents the transition between the static condition and rolling $[17,18]$. In addition to the distinction between static and rolling, most of the solutions are also restricted in other ways, e.g: small values of slip, no spin, no transverse forces, line contact, etc.

The distributions of traction which result from these studies is shown, in general, in Fig. 2(a) for static contact and in Fig. 2(b) for rolling contacts. The traction distribution proffles are representative of those in the plane of rolling ( $x-z$ plane) of an elliptical contact. Line contacts have also been treated with similar results $[7,8]$. The solid lines in $\mathrm{Fig} .2(\mathrm{a})$ and $2(\mathrm{~b})$ represent the traction distribution at some arbitrary overall applied traction force. Traction is limited to $\mu$ times the local Hertzian pressure (the semicircular shaped line). This limiting traction defines the region of slip within the contact. The broken line in Fig. $2(a)$ represents the traction distribution which would occur if no slip took place anywhere in the contact. This is physically impossible since infinite tractions would have to be sustained at the contact perimeter.

The shape of the locked region is one of the key elements in all of the published solutions. In the classical, elastic solution of the static case $[6,16]$, the resulting locked region is (for elliptical contacts) an ellipse, smaller than and similar in shape to the contact ellipse, Fig. 2(c). The reason for this can be seen in $\mathrm{Fig} .2(\mathrm{a})$. Since the infinite traction at the contact boundary cannot be sustained, slip begins at the boundary, and progresses inward as the applied tangential force is increased. For steady rolling contacts, it is generally accepted $[4,5]$ that the locked region 
exists at the leading edge of the contact with respect to the rolling motion. However, the exact shape has been subject to debate. Experimental evidence [10] indicate that the most likely shape is similar to that shown in Fig. $2(d)$. Tangential oisplacement

Static loading. - For two contacting bodies under normal and tangential loading, the tangential surface deflection, $\delta$, of the locked contacting region of one body with respect to points distant in that same body is given by [16].

$$
\delta=\frac{3 \mu N}{4 \pi G a}\left[1-\left(1-\frac{F X}{\mu N}\right)^{2 / 3}\right] \Gamma
$$

where

$$
\Gamma=\left\{\begin{array}{l}
\left(1-v / k^{2}\right) \cdot \pi+v \mathscr{E} / k^{2}, a>b \\
\pi(2-v) / 4, a=b \\
\left(1-v+v / k_{1}{ }^{2}\right) \mathscr{J}_{1}-v \mathscr{E}_{7} / k_{1}{ }^{2}, a<b
\end{array}\right.
$$

and where $\mathscr{F}$ and $\mathscr{E}$ are complete elliptical integrals of the first and second kind, respectively, of argument:

$$
k=\left(1-b^{2} / a^{2}\right)^{1 / 2}
$$

and $\mathscr{F}_{1}$ and $\mathscr{E}_{1}$ are similar integrals of argument:

$$
k_{1}=\left(1-a^{2} / b^{2}\right)^{1 / 2}
$$

The complete elliptical integrals are defined:

$$
\begin{aligned}
& \mathscr{F}=\int_{0}^{\pi / 2}\left(1-k^{2} \sin ^{2} \phi\right)^{-1 / 2} d \phi \\
& \mathscr{E}=\int_{0}^{\pi / 2}\left(1-k^{2} \sin ^{2} \phi\right)^{1 / 2} d \phi
\end{aligned}
$$

The values of $\mathscr{F}$ and $\mathscr{E}$ can be determined from tables, or by using the simplified, curve-fitted equations from [19] summarized in the Appendix. Note that the parameter $\Gamma$ is only a function of Poisson's ratio, $v$, and the 
contact ellipticity ratio, a/b. The dimensions of the locked region are given by

$$
\frac{a^{\prime}}{a}=\frac{b^{\prime}}{b}=\left(1-\frac{F x}{\mu N}\right)^{1 / 3}
$$

where $a^{\prime}$ and $b^{\prime}$ are the semidiameters of the locked ellipse in the $y$ and $x$ directions, respectively [16].

For the case of a sphere on a flat $(a=b)$, Eq. ( 1 ) was tested against experimental values of $\delta[13]$. Predicted deflections exceeded measured values by less than 10 percent.

Rolling contact. - Two contacting bodies which are rolling with a normally steady velocity and tangential load will experience a small, relative velocity difference known as creep. This velocity difference is due to the state of elastic strain in the surfaces as the roller material is swept through the contact region. Material is tangentially stretched and compressed, or vice versa, without gross siliding. Creep is of great engineering importance because the product of creep and tangentlal force is a measure of the power loss.

of the many theoretical investigations preformed $[5,18]$, one study used photoelastic techniques to verify the shape of the locked region in a tangentially loaded, rolling contact [10]. An approximate analytical approach was used in which an elliptical contact is divided into strips oriented parallel to the rolling direction ("strip-theory"), to which the line contact results of $[7,8]$ are applied. The resulting locked region is "lemon-shaped", as shown in Fig. $2(d)$. The center of this locked region lies at a distance, $x$, from the $y$-axis equal to $\left(b-b^{\prime \prime}\right)$. This distance can be determined from: 


$$
\begin{aligned}
\frac{F x}{\mu N}=1-\frac{3}{2}\left\{\left[2 K-K^{2}\right]^{1 / 2}\left[1-\frac{2}{3} K+\frac{1}{3} K^{2}\right]\right. & \\
& \left.-(1-K) \sin ^{-1}\left[\left(2 K-k^{2}\right)\right]^{1 / 2}\right\}
\end{aligned}
$$

where $k=b " / b$

The value of creep is then determined from:

$$
\frac{\Delta U}{U}=\frac{3 \mu N}{G \pi a b}(1-v)\left(1-\frac{b "}{b}\right)
$$

where $\frac{\Delta u}{u}=\frac{\left(u_{1}-u_{2}\right)}{\left(u_{1}+u_{2}\right) / 2}$

and $U_{1}$ and $U_{2}$ are the solid body surface velocities of the two rolling bodies. This predicted creep rate from Eq. (11) agrees with test data generated on a sphere rolling on a flat surface [7] to within ten percent, (average) as illustrated in Fig. 3. Also included on this figure are the predictions from [9, 12]. This particular kalker mode] [12] is a linear one being valid only for the inftial portion of the creep curve.

\section{Application to Traction Rollers}

Application of Eqs. (1) and (11) to traction rollers is complicated by two factors, due to the pivoting rather than translating action of the contact. First, unlike bodies acting purely tangentially, the deflections of bodies pivoting about their axes of rotation under tangential load are not everywhere exactly parallel as assumed in Eqs. (1) and (11). However, this effect is judged to be very small due to the orders of magnitude difference between the rolling radii and the size of the contact. This difference will therefore be neglected in keeping with other studies of contact creep.

The second, more significant effect, is the pivoting action of the contact due to tangential loading which causes fresh unstrained material to enter the contact region unlike translation. For the purely parallel motion case as shown in Fig. 1, the same points on the bodies' contacting surfaces remain 
strained when the bodies are translating in equal and opposite directions. This can be simulated for rollers, if equal and opposite torques are applied such that the "locked" region in the center of the contact doesn't move and remains under the line of centers as shown in Fig. 4(a). However if the center of the driven roller is fixed so that it cannot rotate as a solid body, then the deflection will appear like the exaggerated view in $\mathrm{Fig} .4(\mathrm{~b})$. Since roller surface material on either side of the contact will tend to approach and retreat relative to the other roller surface, the tangential motion tends to Sweep material in and out of the contact as if it were rolling. This implies that the locked region will move toward the leading edge of the contact. This situation is similar to but not strictly the same as in steady rolling. since steady rolling is associated with a steady level of torque while here the tangential load is continuousiy increasing along with the "wind-up" of the driven roller.

For the static deflection of two simple rollers, as in Fig. 4(b), this rolling or "wind-up" motion effect is quite small, typically two orders of magnitude smaller than the contact diameter and can be safely ignored. However, if the output of the drive mechanism is allowed to move or if there is considerable windup of mechanical components downstream of the traction contact to be analyzed, a non-negligible rolling motion will be superimposed on the contact's static displacement.

This time-dependent, "start up" problem has not been treated in the 11terature very often. Numerical solutions appear in $[17,18]$ for calculating the traction distribution of a line contact for start-up rolling under constant tangential load. The numerical results show that the static traction distribution (Fig. 2(a)) completely transforms into a steady rolling distribution (Fig. $2(b)$ ) when the distance rolled is equal to one contact width, $2 b$. 
Since the creep developed is governed by the traction distribution, it is reasonable to conclude that static displacements dominate the motion during the initial interval of rolling. Beyond a distance rolled of one contact width, the creep relations then govern displacements. Between the start of rolling and steady rolling, there is some combination of static and creep displacements. For purposes of this investigation, combining the static and creep displacements in a linear fashion, is expected to provide a reasonable engineering approximation during start up motion.

\section{Deflection and Compliance}

To calculate the total deflection of a pair of traction rollers, therefore, the static case of Eq. (1) will be used, coupled with an approximation of the rolling component. Based on the previously stated assumptions, Eq. (1) can be divided by the rolling radius in order to determine the static angular deflection in radians of the roller surface with respect to its hub. The tangential force, $F_{X}$, can be replaced with applied torque, $T$, divided by rolling radius, $r$, to relate it to torsional load. Making these substitutions, the static torsional angular displacement of one body becomes:

$$
\theta=\frac{3 \mu N}{4 \pi G a}\left[1-\left(1-\frac{T}{\mu N r}\right)^{2 / 3}\right] \Gamma
$$

An expression for torsional compliance is easily found by taking the partial derivative of deflection given in Eq. (12) with respect to torque. The torslonal compllance of one roller, then, is:

$$
C_{T}=\frac{\partial \theta}{\partial T}=\frac{1}{2 \pi G a r^{2}}\left(1-\frac{T}{\mu N r}\right)^{-1 / 3} \Gamma
$$


Alternately, the torsional stiffness, $k_{T}$, of a traction roller is defined as the reciprocal of the compliance.

To approximately account for the rolling induced within the contact in question or transmitted to it, Eq. (11) can be modified. Normally creep is defined using surface velocitles $U_{1}$ and $U_{2}$. However, the relevant factor is not the rate of motion but the motion itself. At constant torque, rolling occurs, and over some small time interval t:

$$
\frac{\Delta U}{U}=\frac{\Delta x / t}{x / t}=\frac{\Delta x}{x}=\frac{x_{1}-x_{2}}{\left(x_{1}+x_{2}\right) / 2}
$$

where $x_{1}$ and $x_{2}$ are the surface motions. Thus Eq. (11) becomes

$$
\frac{\Delta X}{X}=\frac{3 \mu N}{G \pi a b}(1-v)\left(1-\frac{b^{\prime \prime}}{b}\right)
$$

Eq. (15) can be related to angular motion by:

$$
\frac{\Delta \theta}{\theta}=\frac{x_{1} / r_{1}-x_{2} / r_{2}}{\left(x_{1} / r_{1}+x_{2} / r_{2}\right) / 2}
$$

In the results which follow, the deflection based on the rotating component given by Eq. (16) will be combined with the static component given by Eq. (12) to provide an engineering approximation of deflection during startup. This is not strictly correct in comparison with an exact solution due to the differing shapes and locations of the locked area as the statically strained contact transforms into the rolling one. However, as will be seen, the amount of rolling introduced into an otherwise static contact is normally quite small, and thus should have a small effect on contact displacement or compliance. Other factors, such as roller size or the choice of a value for the limiting traction coefficient will have a much larger effect.

This is especially true for the zero torque crossing region where positioning mechanisms spend the bulk of their time "hunting" for position. 
Knowledge of contact compliance in this region is of obvious importance for best dynamic response. The superposition of static and rolling compliance near zero torque will introduce little error, since the contact is in a near total state of elastic strain (negligible internal slip). In any case, contact compliance (slope of displacement curve) is expected to be much less sensitive to either elastic or inelastic rolling than displacement since the total contact strain must be constant and, at all times, globally equal to the applied traction whether the contact is static or rolling.

An understanding of the combination of static (eq. (12)) and creep (eq. (15)) deflections can be obtained using a simple model. The model consists of a pair of rollers in traction contact in which the output shaft of the driven rollers is "grounded" through a shaft (of torsional stiffness GJ/L) attached to fixed structure as shown in Fig. 5 . As torque $T$ is applied to the input roller, the wind up of the shaft causes the output roller to rotate through an angle $\theta_{0}$. Because of rolling creep the input roller must move through a greater angle $\theta_{C}$ given by Eq. (16). This rolling deflection is shown in Fig. 6, for two arbitrary output shafts having dimeters of $1.4 \mathrm{~cm}$ $(0.55 \mathrm{in.})$ and $4.4 \mathrm{~cm}(1.73 \mathrm{in.})$ and a length of $2.5 \mathrm{~cm}(1.0 \mathrm{in.})$. Note that the deflection due to the larger shaft is barely apparent in Fig. 6 . However as output shaft wind up increases with smaller shaft diameter or GJ/L, the rolling deflection increases somewhat. Simultaneousiy, the contact is being statically strained by the increasing torque resulting in an additional angle $\theta_{s}$ in accordance with Eq. (12). This static displacement is not affected by shaft wind up. The net effect on the input roller deflection is the simple summation of $\theta_{c}$ and $\theta_{S}$ as shown by the total line in Fig. 6 . It is clear from this example that the roling deflection component for even an unusually torsionally soft shaft $(d=1.4 \mathrm{~cm})$ is quite small relative to the 
static strain component, as discussed previously. The contact compliance is simply the slope at any point along the total deflection curve.

\section{Other Considerations}

The present analysis pertains to dry contacts. Introduction of lubricant to essentialiy static or slow turning contacts should have little effect, except on reducing the magnitude of the limiting traction coefficient. This is because the surface traction will still be borne by surface asperities. However, the analysis is invalid for steady rolling with lubrication since the pressure distribution is no longer Hertzian and the traction distribution is no longer as assumed but builds with increasing shear as the lubricant film is swept through the contact area [20]. Furthermore, the modulus, G, is some combination of the film-disc system, though at high pressures on steel discs it is primarily governed by the discs [21].

As in the basic Hertz problem, the elastic constants of the two rolling bodies have been assumed to be the same. If they are not, then the norma 1 and tangential traction distributions are not independent. For normal loading alone, tangential displacements are produced in each body which will be unequal if the elastic properties are not the same. The difference in these natural tangential displacements are resisted by friction. Similarly, applied tangential traction will alter the normal pressure distribution. The relative effect is related to the traction coefficient, $\mu$, and an elasticity parameter equal to

$$
x=\frac{\left(1-2 v_{1}\right) / G_{1}-\left(1-2 v_{2}\right) / G_{2}}{\left(1+v_{1}\right) / G_{1}+\left(1+v_{2}\right) / G_{2}}
$$

It has been suggested that for practical values of $\kappa<0.4$ and $\mu<0.2$, the effect of different elasticity constants on the normal pressure distribution and the extent of slip would be small [4]. 


\section{RESULTS AND OISCUSSION}

\section{Varibles Effecting Compllance}

To fllustrate the effects of some of the variables in Eqs. (12) and (13) on static traction roller compliance, a parametric study was conducted. Traction roller contacts can have a broad variety of avallable maximum traction coefficlents, normal loads, ellipticity ratios and applied loading. The relative effects of these variables are important to the designer of a traction drive mechanism which requires a certain level of torsional stiffness. For a given application, usually defined in terms of driven torque load and overall ratio requirement, each of the parameters in Eqs. (12) and (13) can be adjusted, though not totally independently. Besides stiffness, the designer may consider size, weight, fatigue life and efficiency. In each of the four figures which follows, only the relevant variable is changed while the others are held constant.

The effect of tangential force on the relative compliance and deflection of a typical roller pair are plotted in Fig. 7. In this figure, 100 percent $F_{x}$ corresponds to the slip point. Relative deflection and compliance are arbitrarily normalized at $F_{x}=0.5 \mu \mathrm{N}$. Note that the compliance rises from its initial value equal to $(2-v) \Gamma / 2 \pi G a$ at $F_{x}=0$ to infinity at $F_{x}$ $=1.0 \mu \mathrm{N}$. At this upper point, of course, the rollers will totally slide over each other.

The effect of normal load is shown in Fig. 8. Relative deflection and compliance are normalized at $N=2 F_{x} / \mu$. As is apparent from Eq. (13), its effect on compliance is the same as the effect of $I / F_{x}$. Figure 8 shows that increasing normal load causes a small reduction of contact torsional deflection thus improving stiffness. Since contact normal load and applied traction force increase simultaneousiy in traction mechanism designs equipped 
with an automatic loading mechanism, the stiffness increase due to normal load tends to offset the loss in stiffness due to applied torque.

Large variations in stiffness and deflections can be achleved through the choice of the contact geometry. Figure 9 shows the effect of ellipticity ratio on tangential compliance and deflection. Since the contact elipse dimension 'a' appears explicitly in the equations, the figure was plotted by choosing rolling radil, then varying the transverse radil to produce different values of $\mathrm{a}$ and $\mathrm{a} / \mathrm{b}$. As shown in Fig. 9, both deflection and compliance are reduced for contacts narrow in the direction of rolling.

Another important variable is the avallable traction coefficient, $\mu$. The value of $\mu$ is more dependent on material and surface environment than on geometry. The effect of $\mu$ on tangential deflection and compliance is as shown in Fig. 10. In many situations, the value of $\mu$ is not prectsely known, but must be deduced from avallable data on similar contact conditions. For a small change in assumed $\mu$, the effects are small, as long as the applied traction force does not cause the point of gross sliding to be approached.

As might be expected, roller size has a strong effect on torsional stiffness. Consider two situations where the radius can be varied. The first is one where contact conditions are heid constant, (i.e., $F_{x}, N$ and $a / b$ are constant) thus torque scales with radius. Equation (13) reduces to

$$
c_{T} \propto \frac{1}{a r^{2}}
$$

For constant $a / b$, the contact semimajor axis a is related to $N$ and $r$ by:

$$
a \propto(N r)^{1 / 3}
$$

and the transverse radil scale with the rolling radil. Substituting Eq. (19) into Eq. (18), noting that $N$ is constant, and replacing " $r$ "with "size" yields the general size-stiffness relationship: 


$$
k_{T} \propto(s+z e)^{7 / 3}
$$

One should note that contact Hertzian stress, $\sigma_{0}$, can be related to load and radius by

$$
\sigma_{0} \propto N^{1 / 3} r^{-2 / 3}
$$

Since, for this case $N$ is fixed, the effect on stress will be:

$$
\sigma_{0} \propto(\operatorname{size})^{-2 / 3}
$$

The second case is where transmitted torque and the ratio of $F_{x}$ to $\mu N$ are kept constant. To maintain constant torque as the rolling radius changes requires $N \propto 1 / r$. From Eq. (19), with a/b again constant, the ellipse size is constant. Thus Eq. (18) becomes:

$$
k_{T} \propto(s i z e)^{2}
$$

and from Eq. (21) it follows that:

$$
\sigma_{0} \propto 1 /(s i z e)
$$

The foregoing cases show that contact torsional stiffness will more than double for a 40 percent increase in roller size.

\section{Hysteres 1s}

A major advantage of a traction positioning mechanism is the complete lack of backlash. However, due to the fact that inelastic displacements (slip) occur in certain portions of the contact, some hysteresis will be present during torque reversals $[13,15]$. If the rollers of Fig. 5 are positively torqued, then negatively torqued and finally brought back to the original maximum positive torque, a hysteresis loop is generated as shown in Fig. 11. The two loops shown correspond to two maximum torque amplitudes of 20 and 60 percent of the torque to cause gross slip, respectively. Equations for the deflections around the loop along with energy loss are given in [14]. The energy loss is represented by the area bounded by the hysteresis loop. These losses which are 
quite small, steadily increase as the applied torque approaches the torque that will initiate slip. Note that in Fig. 11 , the tips of the loops for each $F_{x} / \mu N$ value define the initial load curve (similar to Fig. 7 ).

\section{Traction Drive}

Using the present analysis, experimental torsional compliance data of a fixed ratio traction drive was analyzed. The test drive consisted of a 14:1 ratio high performance multiroller traction drive [22] of the configuration shown in Fig. 12. The sun roller and ring roller of the planetary configuration serve as input and output (or vice versa) with the nonorbiting planet roller bearings carrying the reaction torque. This traction drive was designed to carry $593 \mathrm{Nm}$ (5250 in. 1b) on the output shaft at $3250 \mathrm{rpm}$ as either a speed increaser or reducer. For normal operation it is lubricated with a synthetic traction oil. It is equipped with a torque responsive roller loading mechanism which controls the normal loads on the rollers so that a constant $F_{x} / N$ is maintained above some adjustable threshold. Below the threshold, the normal loads are constant. For stiffness testing the preload mechanism was defeated and a fixed normal load was set. A fixed normal load is realistic, because a traction positioning mechanism that hunts about zero torque (positive and negative) would be operating below the threshold of variable preload.

For stiffness testing, a residual traction oil film from previous performance testing was left on all components. The roller preload was set at 75 percent of the maximum avallable load. The drive was mounted in its usual housing, and the input (high speed) shaft to the sun roller was rigidly held. Torque was applied in small steps by either a lever arm with deadweights or a hydraulic jack for negative or positive torque, respectively. A torque meter was installed in between the loading arm and the low speed shaft attached to 
the ring roller. Tangential deflection of the traction drive was measured at a radial lug on the outside diameter of the ring roller by means of a dial indicator.

The results of two torque sweeps are shown in Fig. 13. The loading in each case began at zero torque, was stepped up to a maximum, then stepped down through zero to a negative maximum. As can be seen by the trend across zero, there is no backlash (i.e., no discontinuity in the displacement/torque curve). Also apparent from the data is the existence of some hysteresis. Taking all the data as a group, the deflection is nearly linear with torque, at an average stiffiness of approximately $1.8 \times 10^{5} \mathrm{~N} . \mathrm{m} / \mathrm{rad}\left(1.6 \times 10^{6} \mathrm{in} .1 \mathrm{~b} / \mathrm{rad}\right)$ at the ring rolter.

The components within the drive which contribute to stiffness (or compliance) were analyzed. The main contributors included the traction contacts, planet reaction bearings, planet bearing posts, sun roller input shaft and the spline used to fix the sun shaft. The low speed shaft was not included since it was not part of the measurements. Compliance calculations of the planet reaction bearings and the spline on the sun roller shaft were based on formulas appearing in $[23,24]$, respectively. The planet bearing posts and sun roller shaft were idealized and treated with a standard strength of materials approach. In analyzing the individual contacts and other components in the drive, it should be noted that their individual stiffness values must be multiplied by the speed ratio between the component and the low speed shaft squared in order to obtain the effective stiffness at the low speed shaft. This well known effect for drive systems is due to the fact that torque is multiplied by ratio and angular deflection is divided by ratio, hence stiffness changes by $(\text { ratio })^{2}$.

The calculated low speed shaft effective stiffnesses of each set of components are listed in Table I for an applied torque of $282.5 \mathrm{~N} . \mathrm{m}$ (2500 in. 
ib) and a traction contact normal load 75 percent of maximum. A maximum avallable traction coefficlent $\mu=0.2$ was assumed for all traction contacts. Orive stiffness was found to be insensitive to moderate variations of $\mu$ (see Fig. 10). For the three different contacts, the value of $F_{x} / \mu N$ ranged from 0.15 to 0.17 . When the stiffnesses are expressed as equivalents at the output shaft, the components can be treated as torsional springs in series. The total stiffness then is given by

$$
k_{T, \text { DRIVE }}=\left[\sum_{i=1}^{n}\left(k_{T, 1}\right)^{-1}\right]^{-1}
$$

The contribution to deflection of each component is graphically depicted in Fig. 14 over the range of torques. It is important to point out, that the compliance of the traction rollers themselves account for only 2.3 percent of the total compliance of this traction drive. The sun shaft and the planet bearing posts were the most torsionally soft elements.

Comparison of calculated and experimental values reveals an underestimation of the drive's measured torsional compliance by about 44 percent. The authors expect the major portion of error to lie in simplifying assumptions made about the geometry of the sun shaft and bearing posts since these components largely dictate drive compliance.

\section{Comparison to Gear Set}

Using the stiffness analysis developed herein, the stiffness of a roller pair was calculated and compared to two spur gear pairs. The gear pairs used were from the NASA spur gear test rig [25] and a gear pair analyzed in [26]. Table II gives the dimensions of the gears. The compliance of the first gear set was calculated in [27] using the method presented in [28], the compliance of the second was calculated in [26]. These methods take into account the local Hertzian normal compliance, tooth beam bending, undercut and fillet 
bending and shear, and foundation flexiblitity. The calculated stiffnesses are also shown in Table II.

As a comparison, roller pairs of comparable size were chosen to carry the same tangential load. The dimensions of the roller pairs are given in Table II. The resulting torsional stiffnesses were calculated from Eq. (13) for the roller patrs. The results are shown in Table II. For these two examples, the traction roller pairs exceed the corresponding gear pair stiffnesses by approximately 5 and 2 times, respectively. Neither the gears nor the traction rollers were optimized for best stiffness nor for fatigue life, and the effects of support bearings and shafts were not considered. The theoretical fatigue Iife of the traction roller pairs were quite substantial, being approximately 97000 and 40700 hours respectively at $1800 \mathrm{rpm}$ according to the methods of [29]. The results of the comparison indicate that comparatively sized traction rollers can be stiff relative to gear sets.

\section{SUMMARY OF RESULTS}

Tangential compliance theory of two contacting bodies was applied to the case of nonlubricated traction rollers. The conventional assumptions for Hertzian contact were employed. An approximate technique for including static and rolling torsional deflections and compliances was developed. The effects of tangential force, normal load, elipticity ratio, traction coefficient and size on contact stiffness were examined. Traction contact hysteresis effects were also discussed. A torsional compliance analysis of a complete traction drive system was performed and compared to measurements. A comparison was also performed of the stiffness of spur gears and equivalently sized and loaded traction drive rollers.

The following results were obtained: 
(1) Traction drive contacts have relatively high torsional stiffness. In the two cases examined, equivalently sized and loaded traction rollers were approximately 2 and 5 times stiffer than comparable gear sets.

(2) Traction contact stiffness increases with an increase in normal load, avallable traction coefficient and ellipticity ratio or a decrease in tangential force.

(3) At constant traction force, torsional stiffness is proportional to the $7 / 3$ power of roller size, holding normal load and ellipticity ratio constant.

(4) The traction contacts themselves are considerably stiffer than the bearings and other structural elements in a complete traction drive system. These contacts accounted for only 2.3 percent of the total compliance of the traction drive analyzed.

(5) Experimentally determined drive syster stiffness was 44 percent lower than that predicted. 
Appendix - Summary of Curve-fitted Equations for Elliptic Integrals

A simplified procedure for calculating the complete elliptic integrals for use in Hertzian contact problems appear in [19]. For bodies 1 and 2 in contact, planes $x$ and $y$ are the respective planes of maximum and minimum relative curvature for the bodies. These planes, are mutually perpendicular. They are also perpendicular to the plane which is tangent to the contacting bodies' surfaces at the point of contact. Planes $x$ and $y$ should be chosen so that the relative curvature in plane $x$ is greater than in plane $y$, thus:

$$
\frac{1}{r_{1 x}}+\frac{1}{r_{2 x}} \geq \frac{1}{r_{1 y}}+\frac{1}{r_{2 y}}
$$

The direction of rolling is always assumed to be along the $x$-axis. The effective radius is given by:

$$
\frac{1}{R}=\frac{1}{R_{x}}+\frac{1}{R_{y}}
$$

where

$$
\begin{aligned}
& \frac{1}{R_{x}}=\frac{1}{r_{1 x}}+\frac{1}{r_{2 x}} \\
& \frac{1}{R_{y}}=\frac{1}{r_{1 y}}+\frac{1}{r_{2 y}}
\end{aligned}
$$

The radius ratio $x$ is defined as:

$$
a=\frac{R_{y}}{R_{X}}
$$

The contact ellipticity can be calculated from

$$
a / b=(a)^{2 / \pi}
$$


The complete elliptic integrals can be calculated from

$$
\begin{aligned}
& \mathscr{F}=\frac{\pi}{2}+q \ln \alpha \\
& \mathscr{E}=1+q / \alpha
\end{aligned}
$$

where $q=\pi / 2-1$.

For the above assumptions and calculations, $a / b \geq 1$ and $b$ is in the roling direction.

If the assumption of rolling in the $x$ direction causes equation (26) to be violated, then $a / b<1$ and implies rolling w1ll be in the direction of $a$. For this case, if the $x$-axis is still taken to be the rolling direction. Eqs. (29) and (30) will st1ll apply. Then

$$
\begin{array}{r}
\mathscr{J}_{1}=\frac{\pi}{2}-q \ln \alpha \\
\mathscr{E}_{1}=1+q \alpha
\end{array}
$$

Note that in Eq. (29) $\alpha \geq 1$ if Eq. (27) is satisfied and $\alpha \leq 1$ if it is not. The curve fitted equations yield elliptic integrals within a 2.1 percent error and the ellipticlty ratio within a 3.8 percent error for values of a between 0.01 and 100 . 


\section{REFERENCES}

1. Helitich, F. W. and Shube, E. E., Traction Drives: Selection and Application, Dekker, New York, 1983, pp. 5-119.

2. Loewenthal, S. H., Rohn, D. A., and Anderson, N. E., "Advances in Traction Drive Technology," SAE Paper No. 831304, Sept. 1983.

3. Hewko, L. 0., "Roller Traction Drive Unit for Extremely Quiet Power Transmission," Journal of Hydronautics, Vo1. 2, No. 3, July 1968, pp. 160-167.

4. Johnson, K. L., "A Review of the Theory of Rolling Contact Stresses," Wear, Vo1. 9, 1966, pp. 4-19.

5. Kalker, J. J., "Review of Wheel-Rail Rolling Contact Theories," The General Problem of Rolling Contact, AMD-40, ASME, New York, 1980, pp. 77-92.

6. Mindlin, R. D., "Compliance of Elastic Bodies in Contact," Journal of Applied Mechanics, Vol. 16, No. 3, Sept. 1949, pp. 259-268.

7. Carter, F. W., "On the Action of a Locomotive Driving Wheel," Proceedings of the Royal Society of London, Series A, Vol, 112, 1926, pp. 151-157.

8. Poritsky, H., "Stresses and Deflections of Cylindrical Bodies in Contact With Application to Contact of Gears and of Locomotive Wheels, " Journal of Applied Mechanics, Vol. 17, No. 2, June 1950, pp. 191-201.

9. Johnson, K. L., "The Effect of a Tangential Contact Force Upon the Rolling Motion of an Elastic Sphere on a Plane," Journal of Applied Mechanics. Vol. 25, No. 3, Sept. 1958, pp. 339-346.

10. Haines, D. J. and Ollerton, E., "Contact Stress Distributions on Elliptical Contact Surfaces Subjected to Radial and Tangential Forces," Proceedings of the Institution of Mechanical Engineers, Vol. 177, No. 4, 1963, pp. 95-114. 
11. Vermeulen, P. J. and Johnson, K. L., "Contact of Nonspherical Elastic Bodies Transmitting Tangential Forces," Journal of Applied Mechanics, Vol. 31, No. 1, June 1964, pp. 338-340.

12. Kalker, J. J., "On the Rolling Contact of Two Elastic Bodies in the Presence of Dry Friction," WTHD-52, Ph.D. thesis Delft University of Technology, the Netherlands, Aug. 1973.

13. Johnson, K. L., "Surface Interaction Between Elastically Loaded Bodies Under Tangential Forces," Proceedings of the Royal Soclety of London, Sertes $A_{2}$ Vol. 230, No. 1183, 7 July 1955, pp. 531-548.

14. Mindlin, R. 0 , et al., "Effects of an Oscillating Tangential Force on the Contact Surfaces of Elastic Spheres," Proceedings of the First U.S. National Congress of Applied Mechanics, ASME, New York, 1952, pp. 203-208.

15. Mindlin, R. D. and Deresiewtcz, H., "Elastic Spheres in Contact Under Varying Oblique Forces," Journal of Applied Mechanics, Vol. 20, No. 3, Sept. 1953, pp. 327-344.

16. Deresiewicz, H., "Oblique Contact of Nonspherical Elastic Bodies," Journal of Applied Mechanics, Vol. 24, No. 4, Dec. 1957, pp. 623-624.

17. Kalker, J. J., "A Minimum Principle for the Law of Dry Friction, Part 2: Application to Nonsteadily Rolling Elastic Cylinders," Journal of Applied Mechantcs, Vol. 38, No. 4, Dec. 1971, pp. 881-887.

18. Kalker, J. J., "Transient Rolling Contact Phenomena," ASLE Transactions, Vo1. 14, No. 3, Juty 1971, Pp. 177-184.

19. Hamrock, B. J. and Brewe, D., "Simplified Solution for Stresses and Deformations," Journal of Lubrication Technology, Vo1. 105, No. 2, Apr. 1983. pp. $171-177$.

20. Tevaarwerk, J. L. and Johnson, K. L., "The Influence of Fluid Rheology on the Performance of Traction Drives," Journal of Lubrication Technology. Vol. 101, No. 3, July 1979, pp. 266-274. 
21. Loewentha1, S. H. and Rohn, D. A., "Elastic Model of the Traction Behavior of Two Traction Lubricants," ASLE Transactions, Vol. 27, No. 2, Apr. 1984, pp. 129-137.

22. Loewentha1, S. H., Anderson, N. E., and Rohn, D. A., "Evaluation of a High Peformance Fixed-Ratio Traction Orive," Journal of Mechanical Design, Vol. 103, No. 2, Apr. 1981, pp 410-422.

23. Harris, T. A., Rolling Bearing Analysis, Wiley, New York, 1966, pp. $246-247$.

24. Nestorides, E. J., Comp., A Handbook on Torsional Vibration, Cambridge University Press, Combridge, Eng., 1958, pp. 84-97.

25. Townsend, D. P., Coy, J. J., and Zaretsky, E. V., "Experimental and Analytical Load-Life Relation for AISI 9310 Steel Spur Gears," Journal of Mechantcal Design, Vol. 100, No. 1, Jan. 1978, pp. 54-60.

26. Kasuba, R. and Evans, J. W., "An Extended Model for Determining Dynamic Loads in Spur Gearing," Journal of Mechantcal Design. Vo1. 103, No. 2. Apr. 1981, pp. 398-409.

27. Coy, J. J. and Chao, C. H-C., "A Method of Selecting Grid Size to Account for Hertz Deformation in Finite Element Analysis of Spur Gears," Journal of Mechantcal Design, Vol. 104, No. 4, Oct. 1982, pp. 759-766.

28. Corne11, R. W., "Compliance and Stress Sensitivity of Spur Gear Teeth," Journal of Mechanical Design, Vol. 103, No. 2, Apr. 1981, pp. 447-459.

29. Rohn, D. A., Loewenthal, S. H., and Coy, J. J., "Simplifled Fatigue Life Analysis for Traction Drive Contacts," Journal of Mechanical Design. Vol. 103, No. 2, Apr. 1981, pp. 430-439. 
TABLE I. - TOTAL STIFFNESS OF MULTIROLLER TRACTION

ORIVE AT RING TORQUE $=282.5 \mathrm{~N} \cdot \mathrm{m}(2500 \mathrm{in} .1 \mathrm{bf})$

ROLLER NORMAL LOAO 75 PERCENT OF MAX.

\begin{tabular}{|l|c|l|}
\hline \multicolumn{1}{|c|}{ Components } & \multicolumn{3}{|c|}{ Effective stiffness at ring } \\
\hline & N.m/rad & $(1 \mathrm{n} .1 \mathrm{bf} / \mathrm{rad})$ \\
\cline { 2 - 3 } & $1.37 \times 10^{7}$ & $\left(1.21 \times 10^{8}\right)$ \\
Traction contacts & $2.93 \times 10^{6}$ & $\left(2.59 \times 10^{7}\right)$ \\
Planet reaction bearings & $7.47 \times 10^{5}$ & $\left(6.61 \times 10^{6}\right)$ \\
Planet bearing posts & $7.73 \times 10^{5}$ & $\left(6.84 \times 10^{6}\right)$ \\
Sun roller shaft & $1.29 \times 10^{7}$ & $\left(1.14 \times 10^{8}\right)$ \\
Sun roller spline & $3.20 \times 10^{5}$ & $\left(2.83 \times 10^{6}\right)$ \\
\hline \multicolumn{1}{|c|}{ Total } & &
\end{tabular}

TABLE II. - SPUR GEAR AND TRACTION ROLLER DATA AND STIFFNESS COMPARISON

\begin{tabular}{|c|c|c|}
\hline Spur gears & Case 1 & Case 2 \\
\hline $\begin{array}{l}\text { Number of teeth } \\
\text { Diametral pitch } \\
\text { Pressure angle, deg } \\
\text { Pitch diameter, cm (in.) } \\
\text { Tooth width, cm (in.) } \\
\text { Tangential load } \\
\text { at pitch point, } N(1 \mathrm{bf}) \\
\text { Torsional stiffness, } N \cdot \mathrm{m} / \mathrm{rad} \\
\text { (in. } 1 \mathrm{~b} / \mathrm{rad} \text { ) }\end{array}$ & $\begin{array}{c}28 \\
8 \\
20 \\
8.890(3.500) \\
0.625(0.250) \\
1518(341.1) \\
1.47 \times 10^{5}\left(1.32 \times 10^{6}\right)\end{array}$ & $\begin{array}{c}26 \\
8 \\
14.5 \\
8.255(3.250) \\
2.540(1.000) \\
4306(968.1) \\
7.04 \times 10^{5}\left(6.23 \times 10^{6}\right)\end{array}$ \\
\hline $\begin{array}{l}\frac{\text { Traction Rollers }}{\text { Rolling dlameter, cm (in.) }} \\
\text { Avallable traction coefficent } \\
\text { Normal load, N (1bf) } \\
\text { Ellipticity ratio } \\
\text { Contact semimajor dia., cm (in.) } \\
\text { Tangentlal load, N (1bf) } \\
\text { Torsional stiffness, } N \cdot \mathrm{m} / \mathrm{rad} \\
\text { (in. lo/rad) }\end{array}$ & $\begin{array}{c}8.890(3.500) \\
0.2 \\
15180(3411) \\
5.8 \\
.452(.178) \\
1518(341.1) \\
7.06 \times 10^{5}\left(6.25 \times 10^{6}\right)\end{array}$ & $\begin{array}{c}8.255(3.250) \\
0.2 \\
43060(9681) \\
18.2 \\
1.35(.532) \\
4306(968.1) \\
1.38 \times 10^{6}\left(1.22 \times 10^{7}\right)\end{array}$ \\
\hline
\end{tabular}




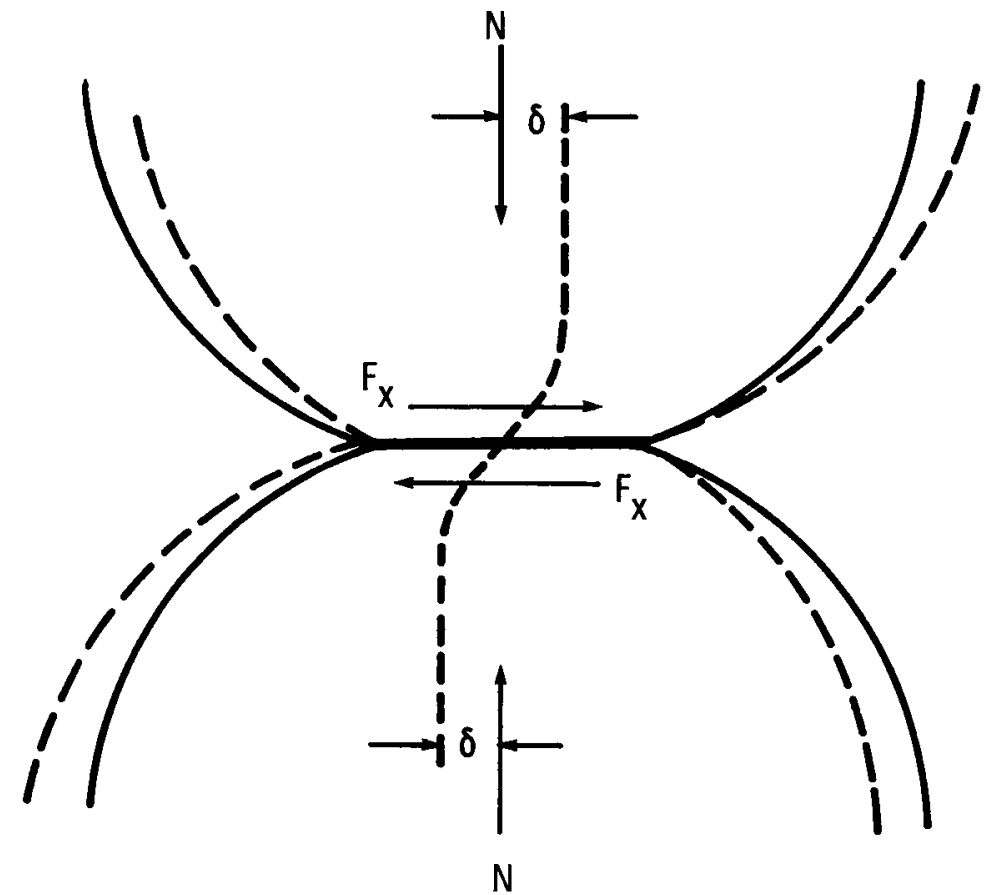

Figure 1. - Tangential deflection $\delta$ of bodies in contact under combined normal $\mathrm{N}$ and tangential $\mathrm{F}_{\mathrm{X}}$ loads. 


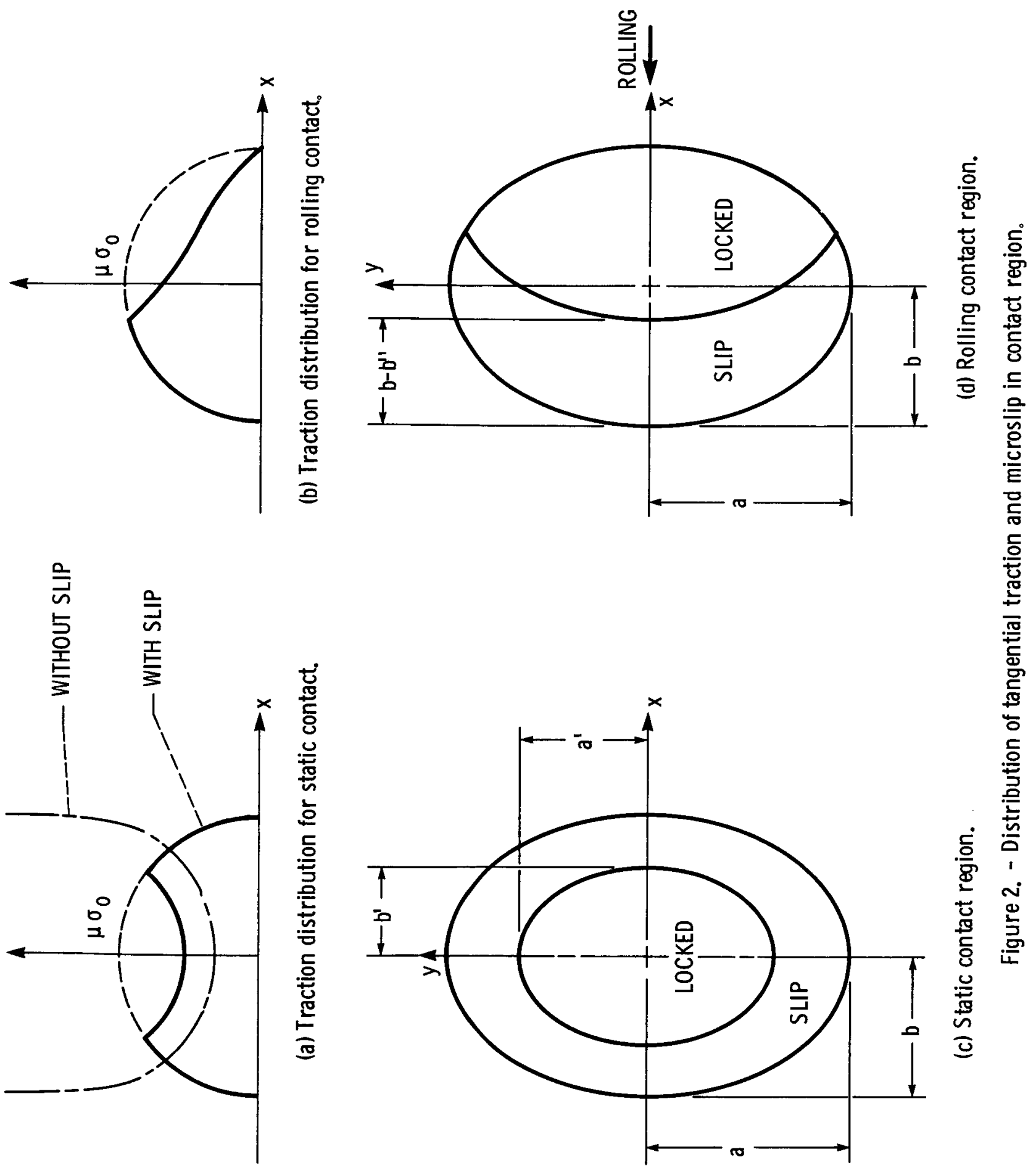



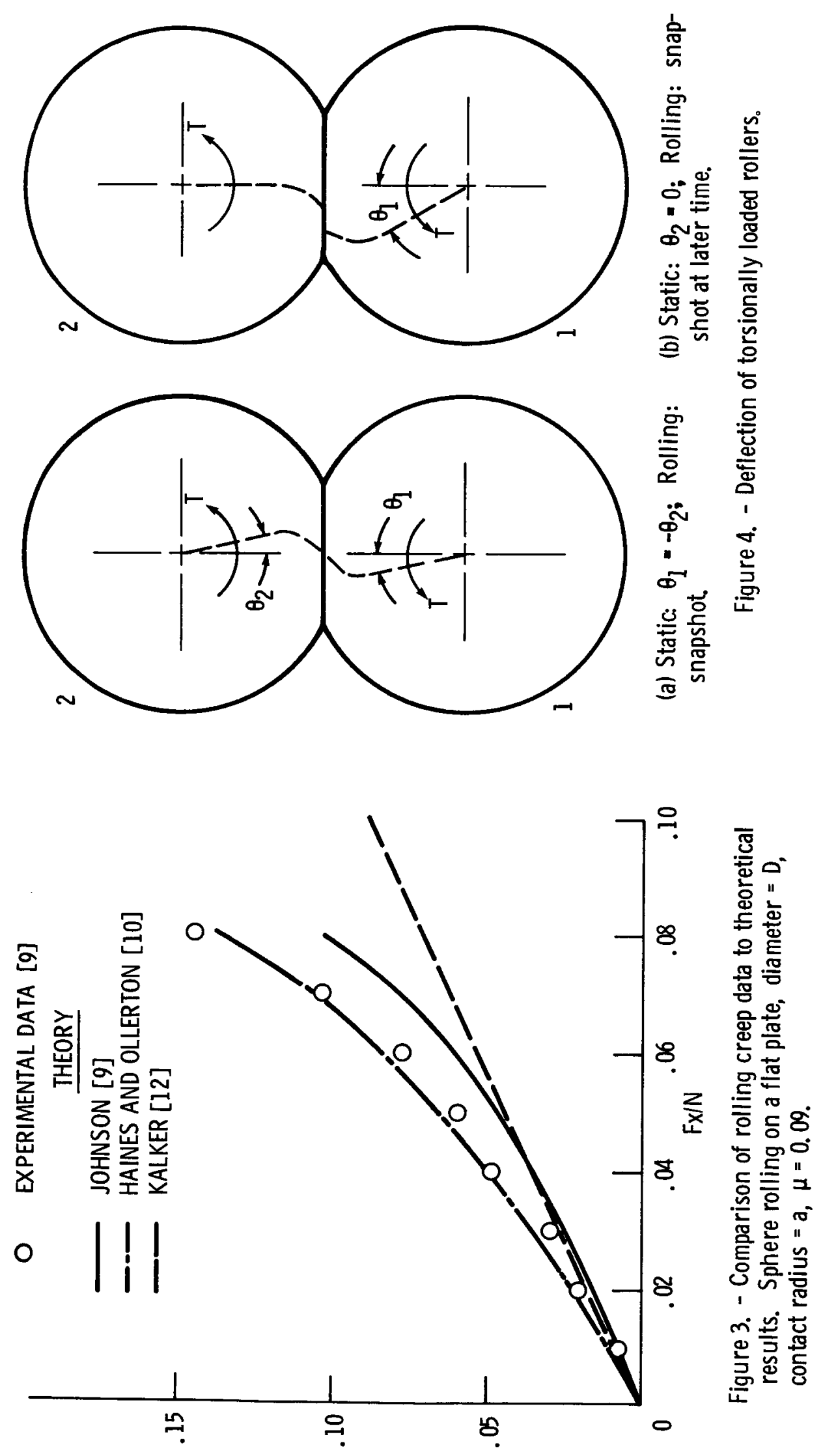

$(\mathrm{e} / \mathrm{\alpha}) \cdot(\mathrm{n} / \mathrm{n} \nabla)$ 

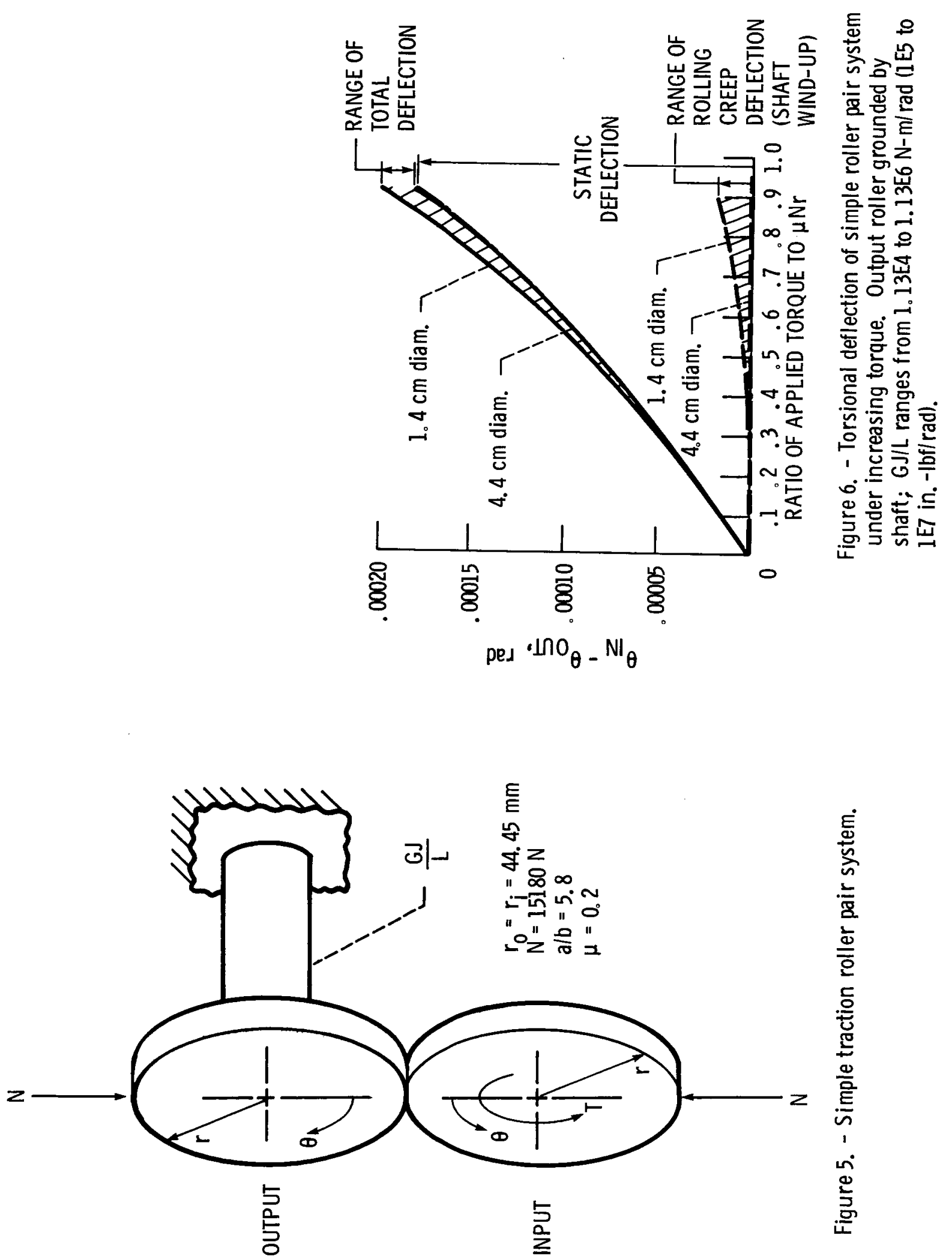


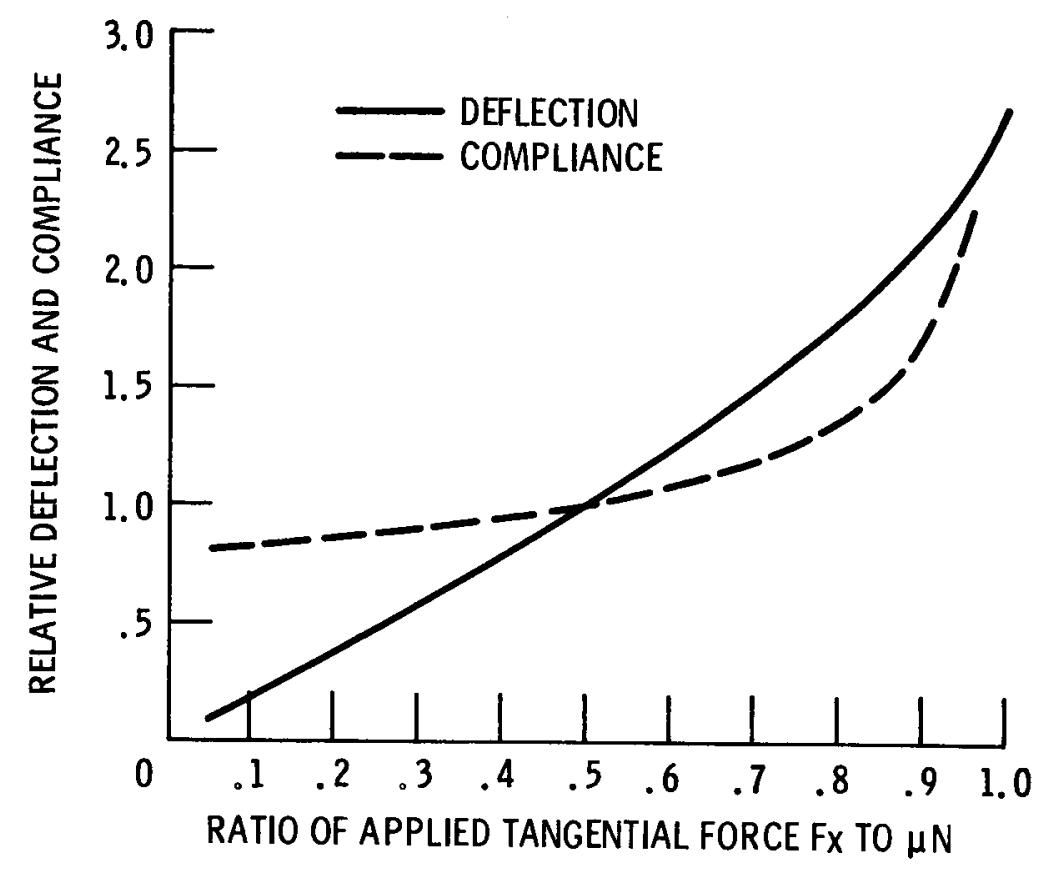

Figure 7. - Effect of tangential load on static torsional deflection and compliance. $N$ and $\mu$ are fixed.

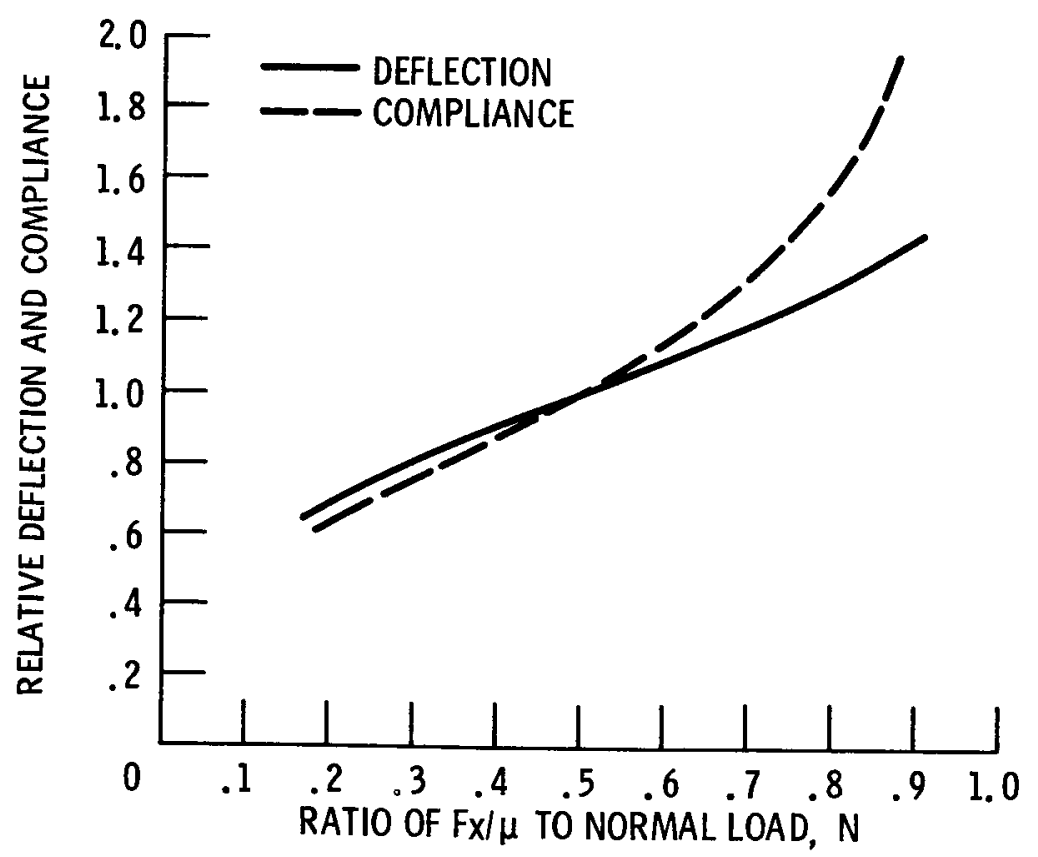

Figure 8. - Effect of normal load on static torsional deflection and compliance. Fx and $\mu$ are fixed. 


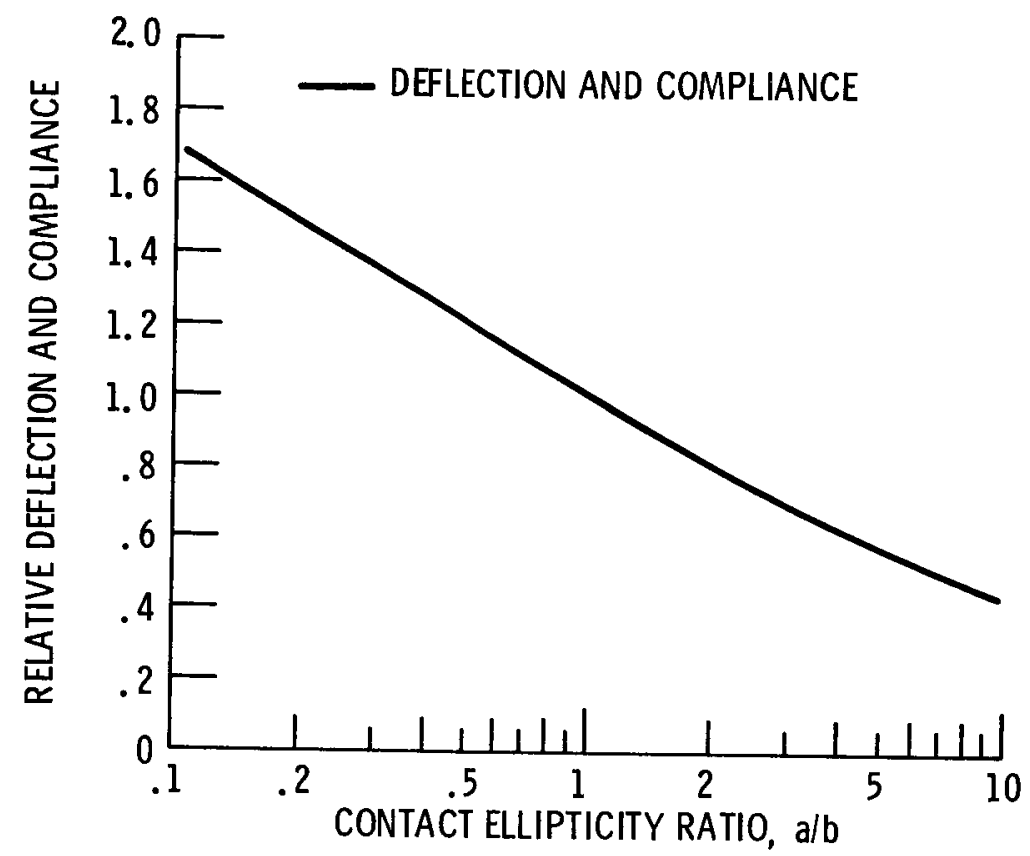

Figure 9. - Effect of ellipticity ratio on static torsional deflection and compliance. Rolling radii fixed, transverse radii varied.

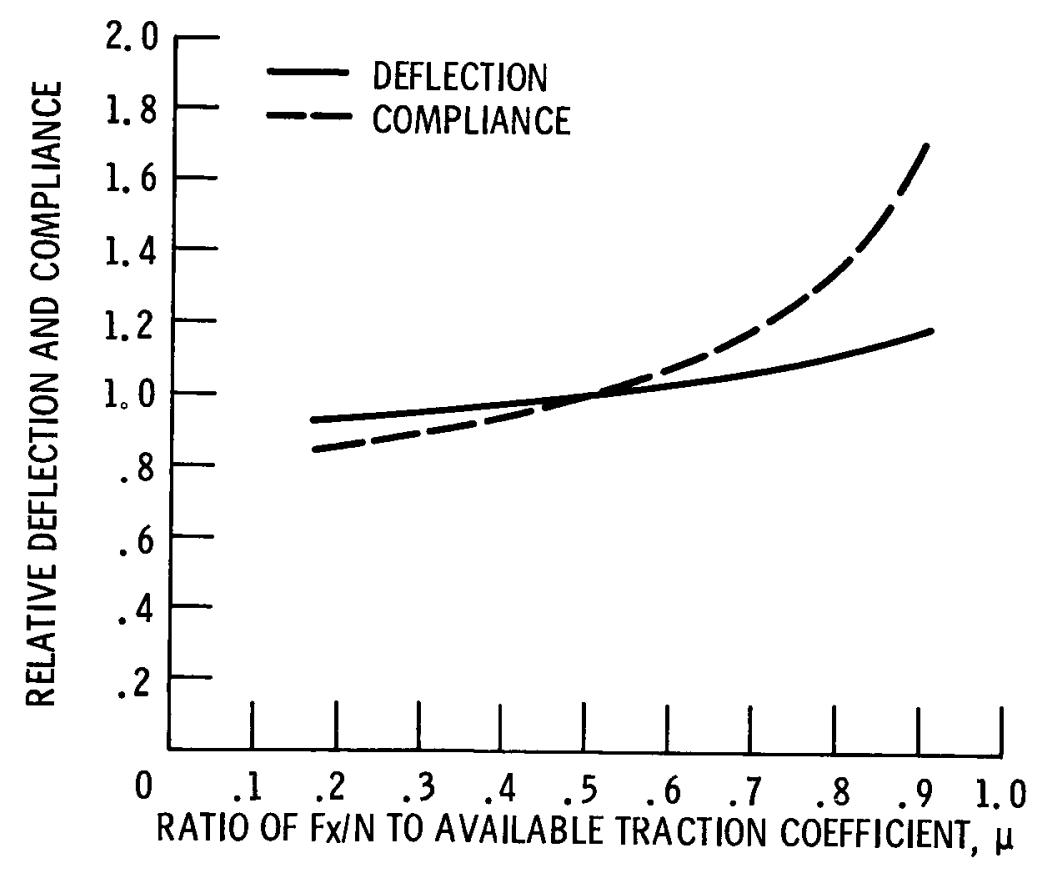

Figure 10. - Effect of available traction coefficient on static torsional deflection and compliance. Fx and $\mathrm{N}$ are fixed. 


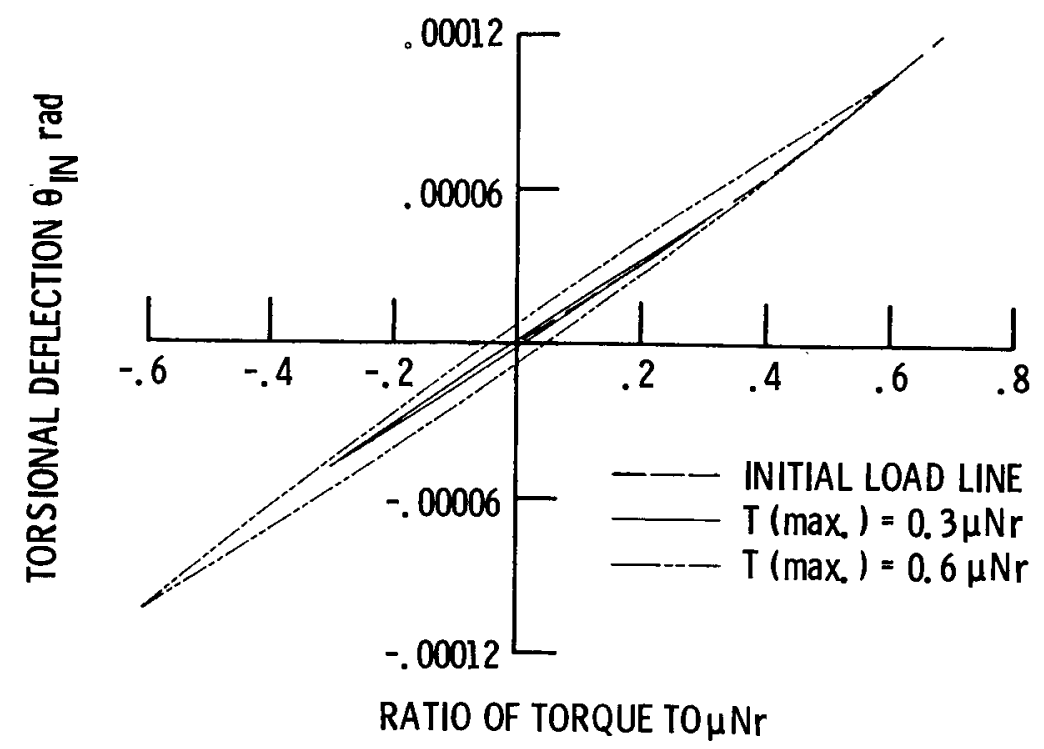

Figure 11. - Typical hysteresis loops for static torsional loading of simple roller pair (see Fig. 5). The torque to cause gross sliding is: $\mathrm{T}=1.0 \mu \mathrm{Nr}$.

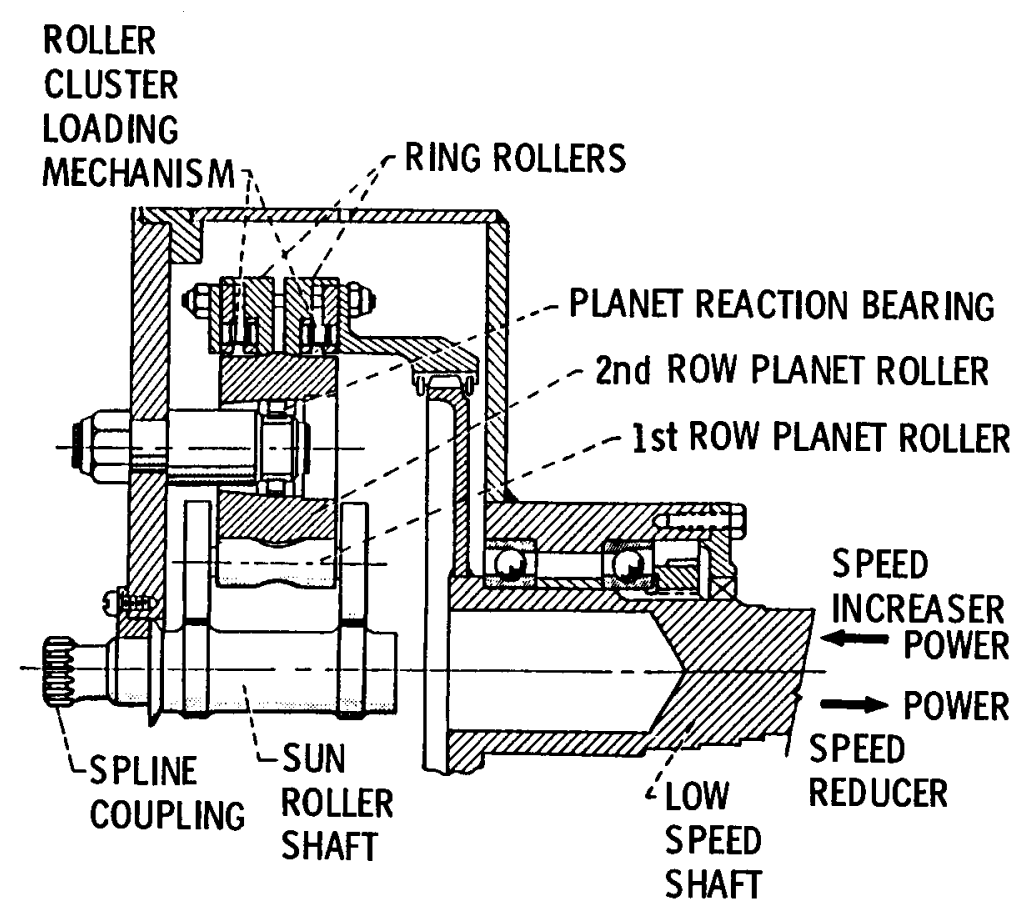

Figure 12. - Basic geometry of Nasvytis multiroller traction drive. 


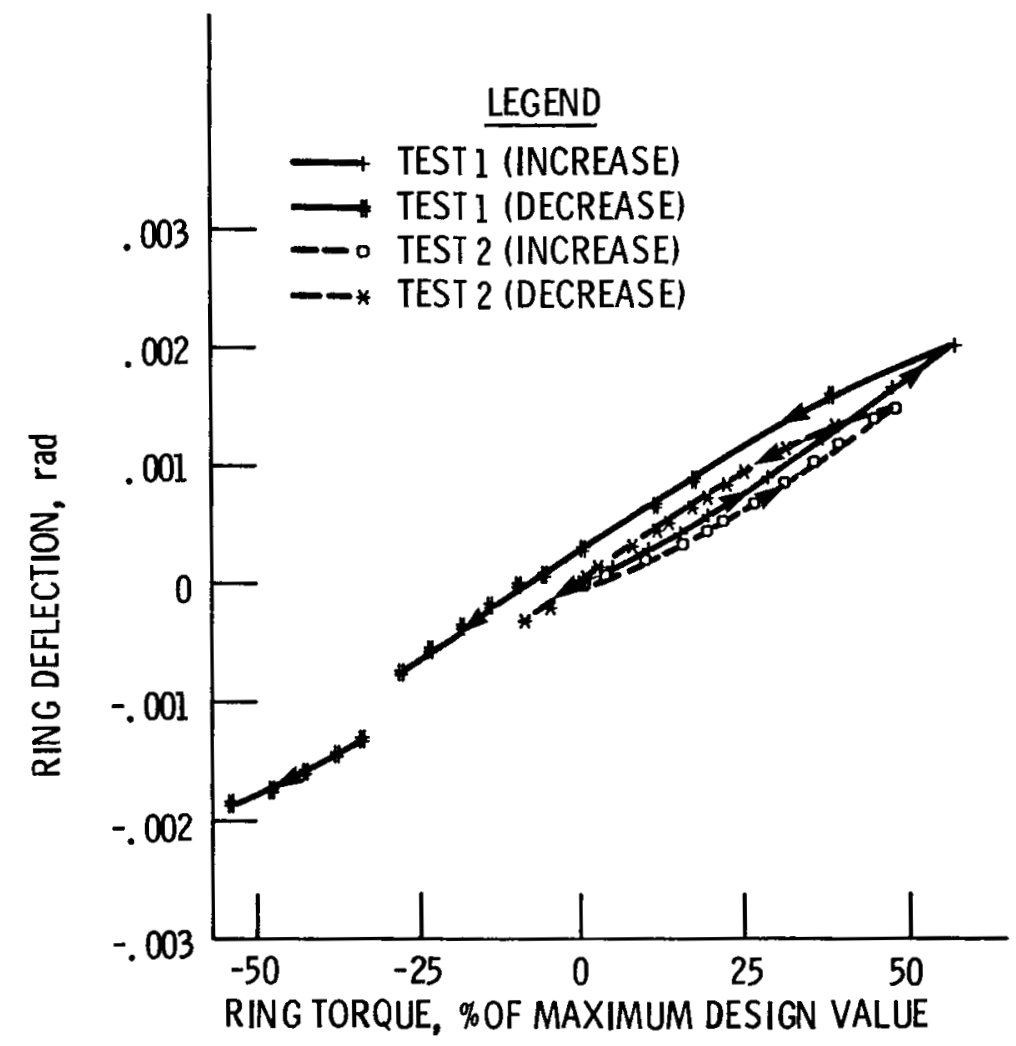

Figure 13. - Traction drive torsional deflection as a function of ring torque. Sun input shaft fixed, roller normal load set at $75 \%$ of max.

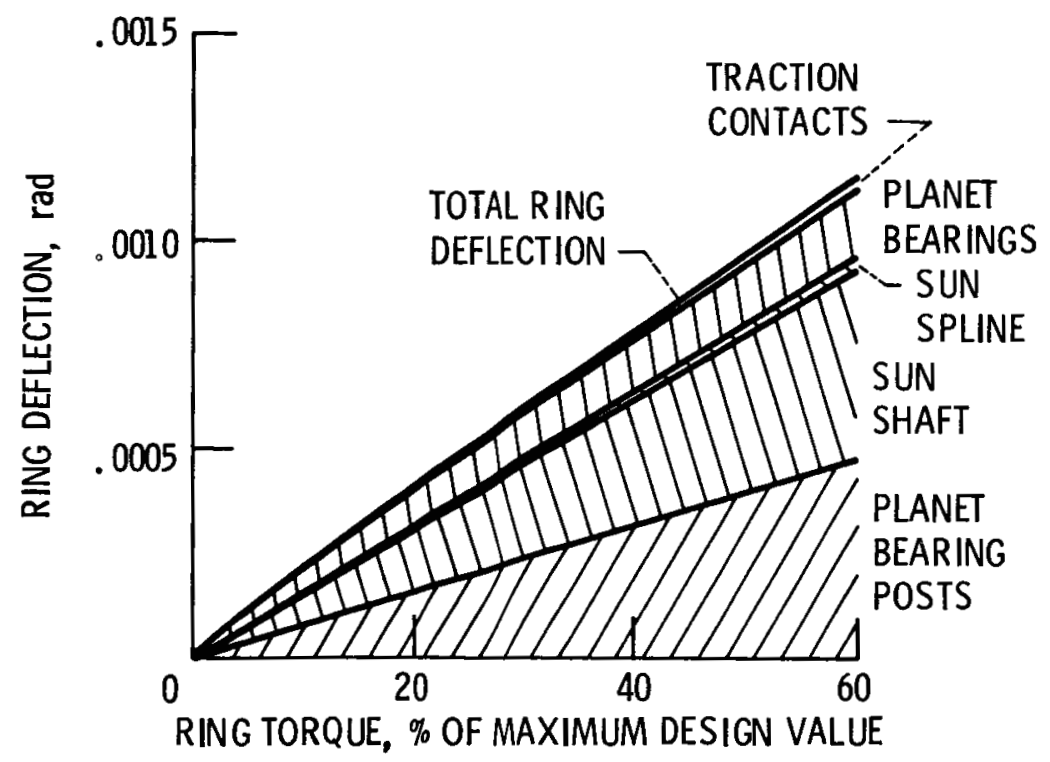

Figure 14. - Component contributions to traction drive deflection. Roller normal load set at $75 \%$ of maximum, $\mu=0.2$. 


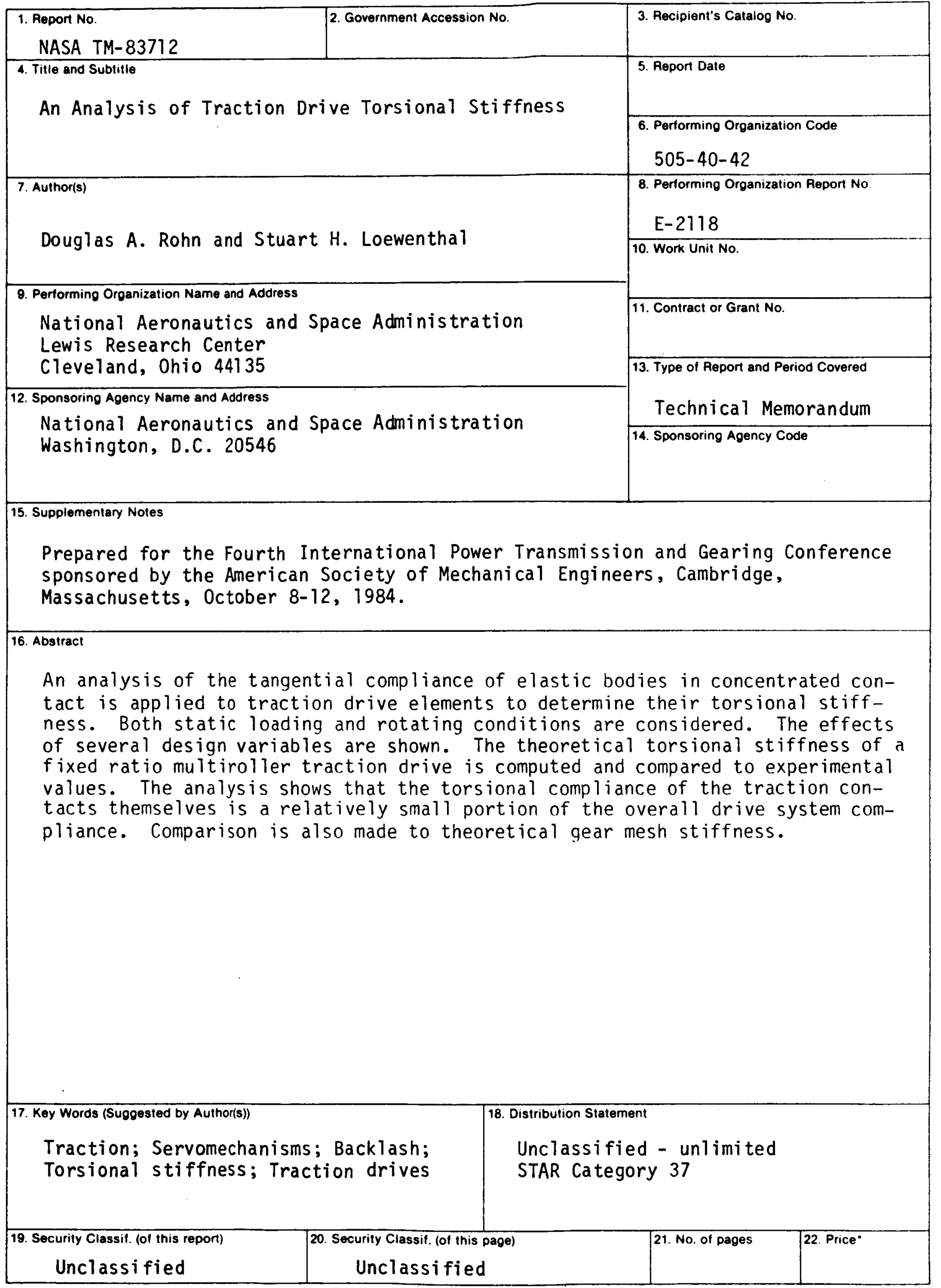

"For sale by the National Technical Information Service. Springfield. Virginia 22161 